Elsevier Editorial System(tm) for Agricultural and Forest Meteorology Manuscript Draft

Manuscript Number: AGRFORMET-D-07-00187R2

Title: ATMOSPHERIC SURFACE LAYER CHARACTERISTICS OF TURBULENCE ABOVE THE PANTANAL WETLAND REGARDING THE SIMILARITY THEORY

Article Type: Research Paper

Section/Category: Micrometerology, incl: (General, theory, Instrumentation, numerical flow modelling)

Keywords: Atmospheric Surface Layer; Heterogeneous surface; Pantanal wetland; Surface energy budget; Monin-Obukhov similarity theory.

Corresponding Author: Edson Pereira Marques Filho,

Corresponding Author's Institution:

First Author: Edson P Marques Filho, PhD

Order of Authors: Edson P Marques Filho, PhD; Leonardo Deane A Sá, PhD; Hugo A Karam, PhD; Regina Célia S Alvalá, PhD; Amaury Souza; Maxsuel Marcos R Pereira, PhD

Abstract: In this manuscript, some micrometeorological characteristics of the Pantanal are presented. This region, one of the greatest wetlands in the world, is located in the central western part of South America. It has very peculiar environmental and ecological characteristics, a great biodiversity and an irregular hydrological cycle, which often presents floods during the wet season and droughts and fires during the dry season. The experimental data were collected in a meteorological tower during the Interdisciplinary Pantanal Experiment (IPE), on April-May 1998. This was a transition period between the wet and the dry season, which a shallow water layer was present at several parts of the experimental field, even around the $25 \mathrm{~m}$ height meteorological tower. The surface energy budget components associated with the existence of the shallow water layer, its diurnal variability and some turbulent variables related to the surface-atmosphere turbulent exchange processes were investigated. Eddy-correlation and variance methods have been used to estimate turbulent fluxes and to study the validity of the Monin-Obukhov similarity theory for the Pantanal region. A mixed layer slab model has been used to estimate the height of the turbulent mixing-layer and to 
provide useful information to test the validity of general relationships concerning horizontal wind velocity variances above Pantanal. In general, the dimensionless relationships between turbulent variables and scaling parameters agree well with the ones found in the literature. Some aspects regarding the heat storage in the shallow water layer present interesting information about its role in the surface-atmosphere energy exchanges processes along the day. 
Dr. Monique Leclerc

Rio de Janeiro, December 05 ${ }^{\text {th }}, 2007$

Associate Editor

Agricultural and Forest Meteorology

Dear Dr. Leclerc

We acknowledge receipt of your journal the request of a second revision of our manuscript entitled: "Atmospheric surface layer characteristics of turbulence above the Pantanal wetland regarding the similarity theory", for which we thank you.

We appreciate again the useful comments and suggestions made by the Reviewers. We believe that these suggestions have permitted the improvement of our manuscript.

We are fortunately able to in a position to send you the proper responses, in the attachment. And we would like to inform you that the reviewed manuscript was electronically resubmitted to the journal Agricultural and Forest Meteorology.

If you please require any further information, do not hesitate to contact us.

Thank you in advance for your consideration.

Yours sincerely,

Dr. Edson P. Marques Filho

E-mail: emarques@acd.ufrj.br

Tel.: ++55.21.81754162 (mobile)

Tel./Fax.:++55.21.25989471 (office)

\section{Corresponding author address:}

Edson P. Marques Filho

Departamento de Meteorologia, Instituto de Geociências, Universidade Federal do Rio de Janeiro (IGEO/UFRJ)

Av. Athos da Silveira Ramos, 274 - Bloco G,

Cidade Universitária, Ilha do Fundão,

Rio de Janeiro, RJ, Brasil, 21949-900 


\section{Answer to the Reviewers}

We want to thank to the Reviewers for the second revision. We appreciate very well the useful suggestions. The answers are enclosed below.

\section{Questions}

1) I wonder if the near jump in the model for $\mathrm{r}_{\mathrm{uw}}$ near $\zeta=-1$ (Fig. 8b) is really supported by the data?

A smooth jump has been observed in the data, which could be adjusted by a sigmoidal function with a relatively small width. This type of fitting is based on the idea of that the correlation coefficients, $r_{\mathrm{wT}}$ and $\mathrm{r}_{\mathrm{uw}}$, are nearly constants along some defined intervals of $\zeta$ (according to Table 2 of Kaimal et al., 1972).

The correlation coefficients can be viewed as a measure of the overall efficiency of the transfer and varies between zero (no correlation) and 1 (optimally efficient transfer) (Roth and Oke, 1995). In accord with these authors the relative transfer efficiencies are given by:

$$
-\frac{\mathrm{r}_{\mathrm{wT}}}{\mathrm{r}_{\mathrm{uw}}}=-\frac{\mathrm{u}_{*} \mathrm{~T}_{*}}{\sigma_{\mathrm{w}} \sigma_{\mathrm{T}}} \cdot \frac{\sigma_{\mathrm{u}} \sigma_{\mathrm{T}}}{\mathrm{u}_{*} \mathrm{u}_{*}}=\frac{\sigma_{\mathrm{u}} / \mathrm{u}_{*}}{\sigma_{\mathrm{T}} / \mathrm{T}_{*}}=\frac{\phi_{\mathrm{U}}}{\phi_{\mathrm{T}}}
$$

where the universal function for the Pantanal are:

$$
\begin{aligned}
& \phi_{\mathrm{U}}(\zeta)=(5.23-7.94 \zeta)^{1 / 3} \\
& \phi_{\mathrm{T}}(\zeta)=(0.02-0.65 \zeta)^{-1 / 3}
\end{aligned}
$$

To verify the sigmoidal fits, the modeled ratio $-r_{w T} / r_{u w}$ was compared with the observed ratio $-r_{\mathrm{wT}} / \mathrm{r}_{\mathrm{uw}}$. Notice that the previously proposed fits in the manuscript was not adequate, as indicated by the Reviewer, because the data seem not to support a jump of first order. For this reason, a revision of the sigmoidal fits was considered below: 


$$
\begin{array}{ll}
\mathrm{r}_{\mathrm{wT}}(\zeta)=0.81\left[\frac{1}{1+\mathrm{e}^{5(\zeta+0.10)}}\right]-0.30 & \text { for }-3 \leq \zeta \leq 2 \\
\mathrm{r}_{\mathrm{uw}}(\zeta)=0.18\left[\frac{1}{1+\mathrm{e}^{5(\zeta+1.25)}}\right]-0.32 & \text { for }-3 \leq \zeta \leq 2
\end{array}
$$

The Figure 1 shows that the new sigmoidal fits are able to adjust the data along the range $-3 \leq \zeta \leq 2$. The new curves are limited by the standard deviation bars, and $\mathrm{r}_{\mathrm{wT}}(\zeta)=0$ at $\zeta=0$.
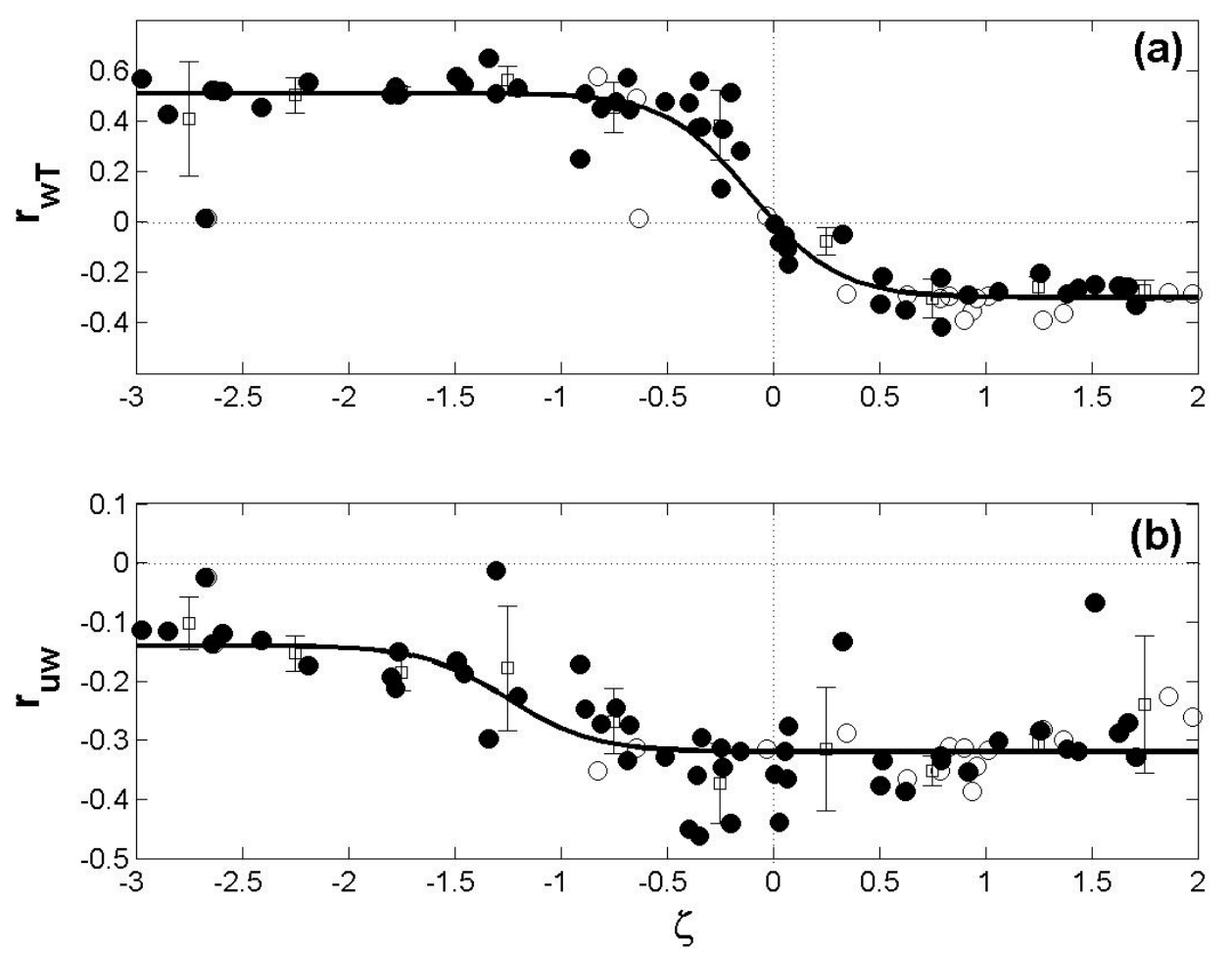

Fig. 1 - Correlation coefficients with the standard deviation bars for: a) heat flux $r_{w T}$; $b$ ) momentum flux $r_{u w}$. The solid lines represent the fitting curves for Pantanal (Eqs. 2a and $2 b)$. The solid and open circles represent the stationary and non-stationary data, respectively. 
To verify the fits, the modeled ratio between the new sigmoidal curves (Eqs. 2a and 2b) is compared with the observed ratio and with the predicted ratio by MOST (Eq. 1). The results are shown in Fig. 2.

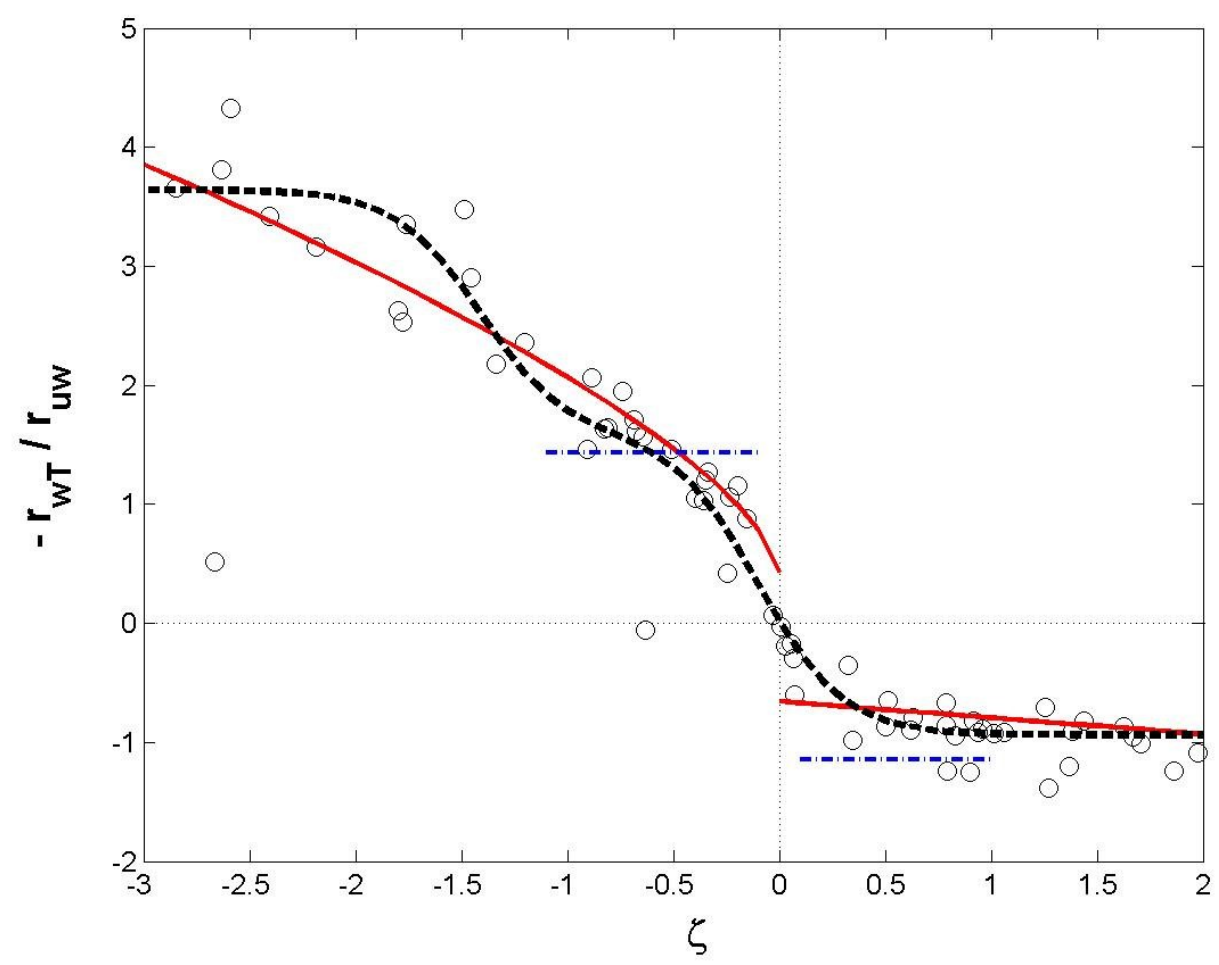

Fig. 2 - Ratio of correlation coefficients versus stability for heat and momentum (open circles). The black dashed line is the modeled ratio (Eqs. 2a and 2b). The red solid lines are the MOST predictions (Eq. 1). The blue dashed-dot lines are the values proposed by Kaimal and Finnigan (1994).

Notice that the observed ratio $-r_{\mathrm{wT}} / \mathrm{r}_{\mathrm{uw}}$ is in agreement with both of the modeled ratio (Eqs. 2a and 2b) and MOST predictions (Eq. 1). The values proposed by Kaimal and Finnigan (1994) are included for comparison and shows significant differences in relation to the observed ratio $-\mathrm{r}_{\mathrm{wT}} / \mathrm{r}_{\mathrm{uw}}$, providing only a rough approximation to the true behavior in the limited range $-1 \leq \zeta \leq 1$. 
2) There are still a number of small English things although the paper is very clearly written.

All the suggested English corrections were implemented in the text.

\section{References}

Kaimal, J. C., Wyngaard, J. C., Izumi, Y, Coté, O. R., 1972. Spectral characteristics of surface-layer turbulence. Quarterly Journal of the Royal Meteorological Society, 98, 563-589.

Roth, M., Oke, T. R., 1995. Relative efficiencies of turbulent transfer of heat, mass, and momentum over a patchy urban surface. . Journal of the Atmospheric Sciences, 52, 1863-1874. 


\section{ATMOSPHERIC SURFACE LAYER CHARACTERISTICS OF TURBULENCE ABOVE THE PANTANAL WETLAND REGARDING THE SIMILARITY THEORY}

E. P. Marques Filho ${ }^{(1)}$, L. D. A. Sá( ${ }^{(2,3)}$, H. A. $\operatorname{Karam}^{(1)}$, R. C. S. Alvalá ${ }^{(3)}$, A. Souza ${ }^{(4)}$, M. M. R. Pereira ${ }^{(5)}$

(1) Departamento de Meteorologia, Instituto de Geociências, Universidade Federal do Rio de Janeiro

(2) Museu Paraense Emílio Goeldi

(3) Instituto Nacional de Pesquisas Espaciais, Centro de Previsão de Tempo e Estudos Climáticos

(4) Departamento de Física, Centro de Ciências Exatas e Tecnologia, Universidade Federal do Mato Grosso do Sul

(5) Programa de Mestrado em Tecnologia Ambiental, Faculdade de Aracruz 


\section{ADDRESSES OF THE AUTHORS:}

\section{Edson Pereira Marques Filho}

Departamento de Meteorologia, Instituto de Geociências, Universidade Federal do Rio de Janeiro

Av. Athos da Silveira Ramos, 274 - Bloco G

Ilha do Fundão - Cidade Universitária

CEP 21941-590 Rio de Janeiro, RJ, Brasil

emarques@acd.ufrj.br

\section{Leonardo Deane de Abreu Sá}

Museu Paraense Emílio Goeldi

Centro de Previsão de Tempo e Estudos Climáticos, Instituto Nacional de Pesquisas

Espaciais

Av. Perimetral, 1901

CEP 66077-530, Belém, PA, Brasil

ldsa@museu-goeldi.br

\section{Hugo Abi Karam}

Departamento de Meteorologia, Instituto de Geociências, Universidade Federal do Rio de Janeiro

Av. Athos da Silveira Ramos, 274 - Bloco G

Ilha do Fundão - Cidade Universitária

CEP 21941-590 Rio de Janeiro, RJ, Brazil

hakaram@acd.ufrj.br

\section{Regina Célia dos Santos Alvalá}

Centro de Previsão de Tempo e Estudos Climáticos, Instituto Nacional de Pesquisas

Espaciais

Av. dos Astronautas, 1758 Jardim da Granja

CEP 12201-970 São Jose dos Campos, SP, Brasil

regina@cptec.inpe.br

\section{Amaury de Souza}

Universidade Federal de Mato Grosso do Sul, Centro de Ciências Exatas e Tecnologia, Departamento de Física.

Cidade Universitaria $\mathrm{s} / \mathrm{n}^{\circ}$

CEP 79070-900 Campo Grande, MS, Brasil

amaury@nin.ufms.br

\section{Maxsuel Marcos Rocha Pereira}

Faculdade de Aracruz, Programa de Mestrado em Tecnologia Ambiental.

Rua Professor Berilo Basílio dos Santos, 180 Centro

CEP 29194-910 Aracruz, ES, Brasil

maxsuelmrp@gmail.com 


\title{
ATMOSPHERIC SURFACE LAYER CHARACTERISTICS OF TURBULENCE ABOVE THE PANTANAL WETLAND REGARDING THE SIMILARITY THEORY
}

\begin{abstract}
In this manuscript, some micrometeorological characteristics of the Pantanal are presented. This region, one of the greatest wetlands in the world, is located in the central western part of South America. It has very peculiar environmental and ecological characteristics, a great biodiversity and an irregular hydrological cycle, which often presents floods during the wet season and droughts and fires during the dry season. The experimental data were collected in a meteorological tower during the Interdisciplinary Pantanal Experiment (IPE), on April-May 1998. This was a transition period between the wet and the dry season, which a shallow water layer was present at several parts of the experimental field, even around the $25 \mathrm{~m}$-height meteorological tower. The surface energy budget components associated with the existence of the shallow water layer, its diurnal variability and some turbulent variables related to the surface-atmosphere turbulent exchange processes were investigated. Eddy-correlation and variance methods have been used to estimate turbulent fluxes and to study the validity of the MoninObukhov similarity theory for the Pantanal region. A mixed layer slab model has been used to estimate the height of the turbulent mixing-layer and to provide useful information to test the validity of general relationships concerning horizontal wind velocity variances above Pantanal. In general, the dimensionless relationships between turbulent variables and scaling parameters agree well with the ones found in the literature. Some aspects regarding the heat storage in the shallow water layer present interesting information about its role in the surface-atmosphere energy exchanges processes along the day.
\end{abstract}

Keywords: Atmospheric Surface Layer; Heterogeneous surface; Pantanal wetland; Surface energy budget; Monin-Obukhov similarity theory. 


\section{Introduction}

The turbulence processes in the atmospheric surface layer (SL) play a major role in the transport of momentum, sensible and latent heat in the atmosphere (Monin and Yaglom, 1971). Particularly, in the SL the turbulent fluxes are essencial for accoplishing atmospheric surface interactions. The SL turbulent structures on horizontally homogeneous surfaces are yet well known (Kaimal and Wyngaard, 1990). The influences of surface heterogeneities have been intensively studied, resulting in proper formulations (Garratt, 1980; Raupach et al., 1996; Jacobs et al., 1997; Andreas et al., 1998; von Randow et al., 2006).

The goal of this work is verifying the validation of the Monin-Obukhov similarity theory (MOST) on the Pantanal wetland, a very large heterogeneous swamp area in central-western Brazil, during a transition period from wet to dry season. Additionally, the surface energy budget and others SL turbulent parameters were computed, discussed and compared with some other research results over complex and flooded terrain. Such pieces of information are also very useful for modeling processes concerning parameterizations above heterogeneous surface (Garratt, 1992).

Even though Pantanal is considered a very important ecosystem, few meteorological investigations have been realized in this region yet. The Interdisciplinary Pantanal Experiment (IPE-1) was the first micrometeorological field campaign carried out in Pantanal, addressed to provide an adequate characterization of the SL structure over the wetland surface, and to obtain useful data for a better understanding of the surface energy budget components associated with the shallow water layer, and some meteorological variables characteristic of the surface-atmosphere turbulent exchange processes. 
The Pantanal ecosystem is one of the larger wetland in the world with near 160,000 $\mathrm{km}^{2}$ (Junk and Cunha, 2005) and UNESCO World Heritage Site. It is located in the center of South America and $85 \%$ of its region belongs to the Brazilian territory, between the states of Mato Grosso and Mato Grosso do Sul. Its boundaries are the Amazonian rain forest on the North, and the Brazilian central plateau on the East. In this region, there is a significant area of tropical savanna grasslands of which Pantanal is an immense sedimentary prairie characterized by a seasonal flooding pattern and peculiar fetch conditions. The climate of Pantanal presents a quasi-regular hydrological cycle with some inter-annual oscillation, which often presents floods during the wet season (November-March), and natural and anthropogenic fires during the dry season (JulyOctober). The precipitation oscillates between 1000-1500 mm year ${ }^{-1}$ and almost $80 \%$ of this precipitation occurs in the summer season, between the months of November and March (Hamilton et al., 1996). The vegetation is typical of an open arboreal savanna region, composed by trees, called Paratudal, rooted floating plants or free floating plants. There are also grass and natural pasture (Por, 1995).

This manuscript is divided in five sections: section two presents the theoretical background; section three describes the experimental site and the data quality control procedure; section four discusses the results; and section five summarizes the conclusions.

\section{Theoretical elements}

The turbulence characteristics in the SL can be described by the universal laws of the MOST under some different stability conditions (Panofsky and Dutton, 1984). Over a horizontally homogeneous surface and under quasi-stationary conditions, the scaling 
turbulent parameters for momentum, temperature, specific humidity and height can be written as:

$$
\begin{aligned}
& \mathrm{u}_{*}=\left[\left(\overline{\mathrm{u}^{\prime} \mathrm{w}^{\prime}}\right)_{0}^{2}+\left(\overline{\mathrm{v}^{\prime} \mathrm{w}^{\prime}}\right)_{0}^{2}\right]^{1 / 4} \\
& \mathrm{~T}_{*}=-\left(\overline{\mathrm{w}^{\prime} \mathrm{T}^{\prime}}\right)_{0} / \mathrm{u}_{*} \\
& \mathrm{q}_{*}=-\left(\overline{\mathrm{w}^{\prime} \mathrm{q}^{\prime}}\right)_{0} / \mathrm{u}_{*} \\
& \mathrm{~L}=-\mathrm{u}_{*}^{3} / \kappa g\left(\frac{\mathrm{w}^{\prime} \mathrm{T}^{\prime}}{\mathrm{T}_{0}}+0.61 \overline{\mathrm{w}^{\prime} \mathrm{q}^{\prime}}\right)
\end{aligned}
$$

where $\mathrm{u}^{\prime}, \mathrm{v}^{\prime}$ and $\mathrm{w}^{\prime}$ are the fluctuations of the wind velocity components; $\mathrm{T}^{\prime}$ and $\mathrm{q}^{\prime}$ are the fluctuations of temperature and specific humidity, respectively; $\mathrm{u}_{*}$ is the velocity scale; $\mathrm{T}_{*}$ and $\mathrm{q}_{*}$ are the temperature and humidity turbulent characteristic scales, respectively; $\mathrm{L}$ is the Obukhov length scale; $\mathrm{g}$ is the gravity acceleration; and $\mathrm{\kappa}$ is the von Karmán constant ( $\kappa=0.4)$ (Högström, 1996).

For many SL applications, it is necessary to have information about the characteristics of the vertical profiles and turbulent fluctuations of the micrometeorological variables (Sorbjan, 1986; Viswanadham et al., 1990; Garratt, 1992).

The MOST predicts that the turbulent characteristics near the ground are related to the universal functions, $\phi$, through of the stability parameter $\zeta=\mathrm{z} / \mathrm{L}$, where $\mathrm{z}$ is the height over the ground. Therefore, the dimensionless standard deviations of the wind velocity components $\sigma_{\mathrm{u}, \mathrm{v}, \mathrm{w}} / \mathrm{u}_{*}$ and temperature $\sigma_{\mathrm{T}} / \mathrm{T}_{*}$ should be obtained (Sorbjan, 1989; Kader and Yaglom, 1990; Högström, 1996) as:

$$
\phi_{\mathrm{i}}(\zeta)=\frac{\sigma_{\mathrm{i}}}{\mathrm{u}_{*}}= \begin{cases}\left(\mathrm{a}_{\mathrm{i}}+\mathrm{b}_{\mathrm{i}} \zeta\right)^{1 / 3} & \text { for } \zeta<0 \\ \left(\mathrm{c}_{\mathrm{i}}+\mathrm{d}_{\mathrm{i}} \zeta\right) & \text { for } \zeta>0\end{cases}
$$


$\phi_{\mathrm{T}}(\zeta)=\frac{\sigma_{\mathrm{T}}}{\mathrm{T}_{*}}= \begin{cases}\left(\mathrm{a}_{\mathrm{T}}+\mathrm{b}_{\mathrm{T}} \zeta\right)^{-1 / 3} & \text { for } \zeta<0 \\ \left(\mathrm{c}_{\mathrm{T}}+\mathrm{d}_{\mathrm{T}} \zeta\right)^{-1} & \text { for } \zeta>0\end{cases}$

where $a_{i, T}, b_{i, T}, c_{i, T}$ and $d_{i, T}$ are universal constants, with $i=(u, v, w)$. In this study, the appropriate length scale used to compute $\zeta$ is $(z-d)$, the effective height above the zero-plane displacement, $d$. The universal constants in the Eqs. (2a and 2b) are generally determined by field experiments (Sorbjan, 1986; Kader and Yaglom, 1990; Högström, 1996; Khanna and Brasseur, 1997; Andreas et al., 1998) and here, they have been obtained by least square method. There are still some disagreements concerning the application of the MOST for data measured over heterogeneous surfaces, especially over forests and water paths (Thom et al., 1975; Garratt, 1980; Raupach et al., 1996; Sun et al., 1996; Marht, 1999).

\section{Experimental site and data analysis}

The IPE-1 was conducted during the transition period between the wet and the dry seasons, i.e. on April and May of 1998. The experimental site is located in the southern region of Pantanal wetland $\left(19^{\circ} 34^{\prime} \mathrm{S}, 57^{\circ} 01^{\prime} \mathrm{W}\right.$, altitude $\left.80 \mathrm{~m}\right)$ in Mato Grosso do Sul State, Brazil. A $21 \mathrm{~m}$-height instrumented tower, with a supplementary $4 \mathrm{~m}$ mast erected at its end, was built on a vegetated terrain covered by a shallow water layer with 7 to 15 cm-depth.

The turbulent measurements at the level of $25 \mathrm{~m}$ for the wind velocity components $\left(\mathrm{u}^{\prime}, \mathrm{v}^{\prime}, \mathrm{w}^{\prime}\right)$ and temperature $\left(\mathrm{T}^{\prime}\right)$ were acquired at a sampling rate of $21 \mathrm{~Hz}$ (Gill-Solent sonic anemometer), for a period of six rain-free days. The slow response data of mean wind velocity (U) (Vector Instruments anemometer), air temperature (T) and specific humidity (q) (Campbell psycrometer), were measured at 6 different levels $(2.0,3.75$, 
8.1, 9.75, 15.7 and 21.5 meters). The net radiation $\left(\mathrm{R}_{\mathrm{n}}\right)$ (REBS net radiometer) was measured at 4 and 20.4 meters above the surface. The soil temperature $\left(\mathrm{T}_{\mathrm{s}}\right)($ Campbell thermistor) and the soil heat flux $\left(\mathrm{G}_{\text {out }}\right)$ (REBS fluxmeter) were measured at 3 different depths into the ground $(-1,-2$ and $-10 \mathrm{~cm})$, i.e. below the shallow water layer. All the slow response measurements were recorded at a sampling rate of 10 minutes.

The data quality control procedure of Vickers and Mahrt (1997) was applied to remove spikes and missing portions of the turbulent measurements. Many phenomena can lead to non-stationary series such as diurnal trends, mesoscale circulations, and surface heterogeneity (Mahrt et al., 1994; Sun et al., 1996; von Randow et al., 2002). They can affect the surface fluxes estimate by eddy-correlation (EC). The nonstationarity of the Pantanal data series was identified by the methodology of Mahrt (1998). The result indicates that $35 \%$ of the records are non-stationary, mainly during the late afternoon and at night. However, the nonstationary data seems not increase significantly the scattering of the standard deviation and correlation coefficients in the range $-3 \leq \zeta \leq 2$, as will be showed in the next section.

The low-pass filter based on wavelets transforms (Daubechies, 1992) was applied to the turbulent data for removing the very low frequency fluctuations (cutoff $\mathrm{f} \leq 2 \times 10^{-3} \mathrm{~Hz}$ ), after the coordinate system has been aligned with the mean wind direction. On the other hand, a recursive digital filter (Otnes and Enochson, 1972) was applied in the slow response measurements to assure greater accuracy in the $\mathrm{U}, \mathrm{T}$ and $\mathrm{q}$ vertical gradient calculations.

The temporal evolution of micrometeorological parameters in SL was obtained for every $\tau=60$ minutes data window. According to Shuttleworth et al. (1984), the choice of the appropriate $\tau$ value takes in account two conditions: (a) it should be long enough to include most of the low frequency contributions in the co-spectra between vertical 
wind speed and the other fluctuations meteorological variables; (b) at the same time, very large values of $\tau$ could make the flux susceptible of contamination by low frequency correlations associated with mesoscale motions, or due instrument-generated spurious correlations.

In IPE-1, the average wind velocity was smaller than $4 \mathrm{~m} \mathrm{~s}^{-1}$, the virtual temperature was between $13.5{ }^{\circ} \mathrm{C}$ and $37.4{ }^{\circ} \mathrm{C}$, and the specific humidity was between $9 \mathrm{~g} \mathrm{~kg}^{-1}$ and $28.5 \mathrm{~g} \mathrm{~kg}^{-1}$.

\section{Analyses and results}

The SL turbulent flow above very rough surfaces is dynamically influenced by the average roughness as well as by individual elements present on the surface. It has very complex characteristics compared with the turbulent flow above smooth and horizontally homogeneous surfaces (Garratt, 1980; Viswanadham et al., 1990; Raupach et al., 1996; von Randow et al., 2002).

In general, to express the action of a complex surface drag in the atmospheric flow, two aerodynamic parameters are used: the zero-plane displacement $\mathrm{d}$ and the roughness length $\mathrm{z}_{0}$ (Thom et al., 1975). The former indicates the vertical level where the mean wind, extrapolated from above, approaches zero, and should be considered the level of action of the surface drag by the main roughness elements (Thom, 1975). According to

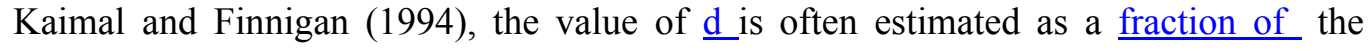
canopy layer height, $\mathrm{h}_{\mathrm{c}}\left(\mathrm{d} \approx 0.75 \mathrm{~h}_{\mathrm{c}}\right)$.

The accurate determination of $d$ requires adequate fetch conditions and instrumental measurements at heights greater than $h_{c}$ (Wieringa, 1993). De Bruin and Verhoef (1997) suggested an alternative method to estimate $d$ through the similarity relationships 
associated with the estimated standard deviation of the vertical wind velocity $\left(\sigma_{\mathrm{w}}\right)$ under free convection condition, which has been used in this investigation. This procedure allows a proper determination of $d$ with fast response $w^{\prime}$ and $T^{\prime}$ data measured only at one height.

In this study was considered the following criterion to free convection definition, $\zeta<-2$, which is consistent with the preposition by Kader and Yaglom (1990). Considering only the values of $d$ found in the range limited to two standard deviation from the average, $\mathrm{d}$ is equal to $4.96 \pm 0.56$ for the Pantanal. This value is similar to the value could be obtained with the Kaimal and Finnigan (1994) simplified methodology $\left(\mathrm{d} \approx 0.75 \mathrm{~h}_{\mathrm{c}} \approx 5 \mathrm{~m}\right)$.

\subsection{Surface energy budget}

The surface energy budget (SEB) is associated with the SL turbulent structure. Therefore, the shallow water layer (SWL) on the Pantanal area must be considered. Following Oke (1987) and Jacobs et al. (1997), the SEB on the interface of the SWL may be written as (Fig. 1):

$$
\mathrm{R}_{\mathrm{n}}=\mathrm{H}+\mathrm{LE}+\mathrm{G}_{\text {in }}
$$

where $\mathrm{H}$ is the sensible heat flux; LE is the latent heat flux; and $\mathrm{G}_{\mathrm{in}}$ is the heat flux into SWL. $\mathrm{H}$ is estimated by the EC method; $\mathrm{G}_{\mathrm{in}} \approx \mathrm{R}_{\mathrm{n}}-\mathrm{H}-\mathrm{LE}$ is computed as a residual term of the SEB (Eq. 3); and $\mathrm{G}_{\text {out }}$ is the measured soil flux just below the SWL (Fig. 1). The SWL energy storage, $\Delta \mathrm{S}$, is estimated as $\Delta \mathrm{S} \approx\left|\mathrm{G}_{\mathrm{in}}\right|-\left|\mathrm{G}_{\text {out }}\right|$. Since q' measurements were not available during the IPE-1 experimental campaign, LE has been obtained indirectly by the Bowen ratio energy balance method, as suggested by Liu and Foken (2001). 
The Bowen ratio $\beta$ was estimated using the slow response measurements of $\mathrm{T}$ and $\mathrm{q}$, according to the equation below:

$$
\beta=\frac{\mathrm{c}_{\mathrm{p}}}{\mathrm{L}_{\mathrm{v}}} \frac{\Delta \overline{\mathrm{T}}}{\Delta \overline{\mathrm{q}}}
$$

where $\Delta \overline{\mathrm{T}}$ and $\Delta \overline{\mathrm{q}}$ are, respectively, the mean differences of temperature and specific humidity, respectively, at two vertical levels near to ground; $c_{p}$ is the specific heat of air at constant pressure; and $\mathrm{L}_{\mathrm{v}}$ is the latent heat of vaporization for water.

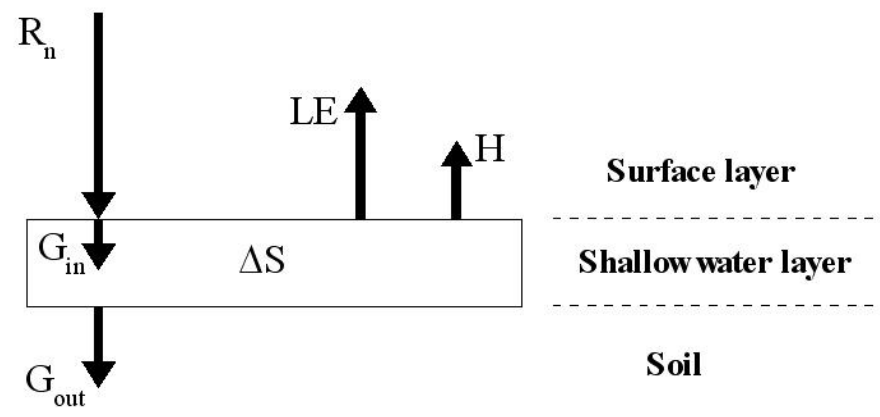

Figure 1 - Schematic overview of the shallow water layer energy budget under diurnal conditions.

The temporal evolution of the SEB components is presented in the Fig. 2. The focus of our analysis is the daytime partition of the energy. On average, for Pantanal, the mean $\beta$ is near $0.36 \pm 0.01$, which is lower than the mean value of 0.4 estimated above the Amazonian rain forest (von Randow et al., 2002). This indicates the great energy availability for water evaporation on the Pantanal surface. 
The SWL contains a lot of embedded vegetation. The presence of vegetation should imply a specific radiation transfer through the depth of the water body and a particular energy budget. During the first hours in the morning, the surface of the SWL quickly warms due to the absorption of the incoming solar radiation, allowing the occurrence of a mean SWL temperature greater than in the soil surface bellow $(\Delta \mathrm{S}>0)$. In the next hours, the SWL is able to transfer heat to the ground (Fig. 2). Thus, $\Delta \mathrm{S}$ remains negative until the end of the afternoon.

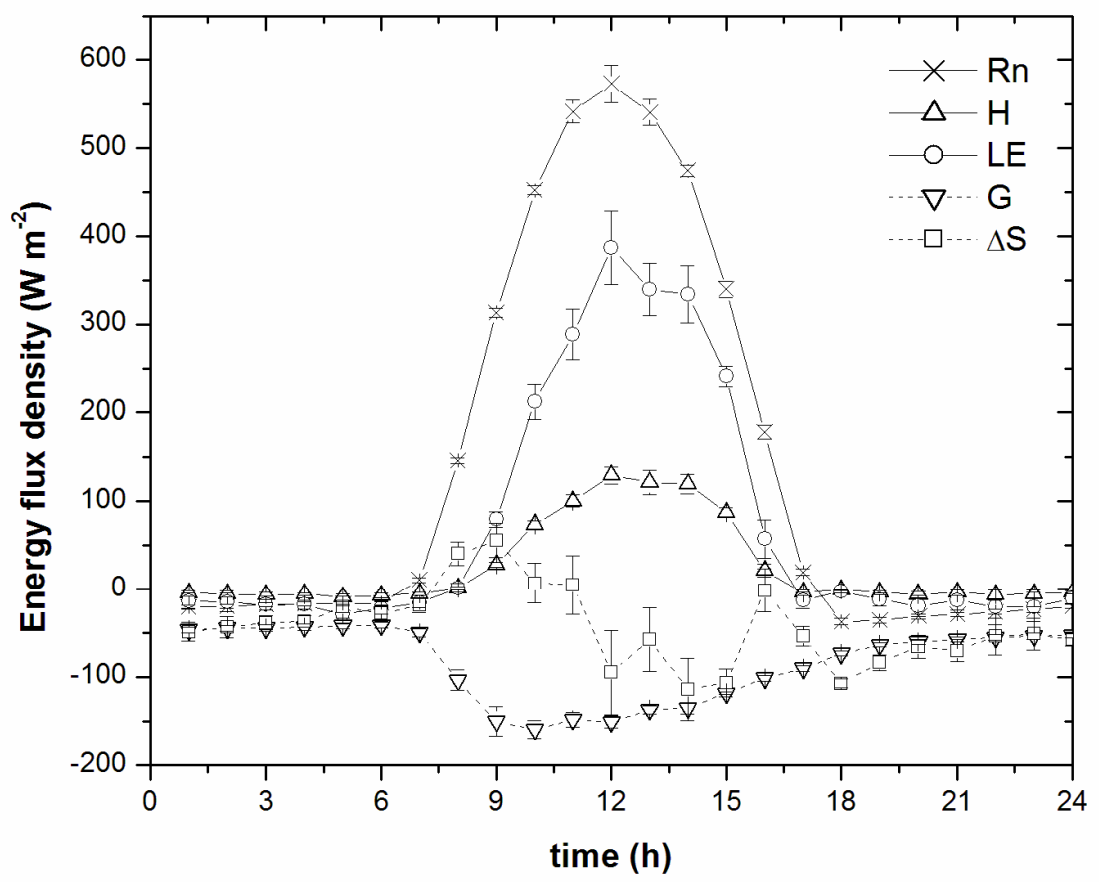

Figure 2 - Temporal evolution of the surface energy budget mean components for the Pantanal region with the respective standard deviations bars.

In order to introduce useful information for discussion, we will consider Jacobs et al. (1997) reasoning, one of the few available environmental results regarding the energy budget in a SWL. Comparatively, the SWL depth presented by Jacobs et al. (1997) is 
thicker than the one in Pantanal. Consequently, our SWL warms faster and stores less heat than theirs. The picks and valleys, notable on the $\Delta \mathrm{S}$ line, are probably associated to large term differences used to compute the residue of Eq. (3).

Another peculiar characteristic of the SEB in Pantanal is that the SWL provides a thermal insulation of the ground. Hence, the heat soil flux $G_{\text {out }}$ is always downwards, even during the night.

These behaviors are considered a regional characteristic of Pantanal area in the wet season from a qualitative point of view. In the dry season, the SWL completely evaporates and the soil is exposed to the solar radiation heating, resulting in another distinct energy budget that will be the subject of new studies. Despite the short period of the experimental campaign the intention of this work was describing the dynamics and thermodynamics features usually found in the Pantanal SL, and establishing a methodology useful to the data analysis.

\subsection{Applicability of Monin-Obukhov Similarity Theory}

\section{a) Standard deviation of temperature}

The applicability of the MOST is verified by performing an analysis of $\mathrm{H}$ estimates, considering both the EC $\left(\mathrm{H}_{\text {eddy }}\right)$ and the variance $\left(\mathrm{H}_{\mathrm{var}}\right)$ methods. In the literature, Lloyd et al. (1991) have shown that the variance method reproduces very well the $\mathrm{H}$ estimates by the EC method for four different surface types. Katul et al. (1995) made a review about the variance method above uniform and non-uniform terrains. Other authors also have used this technique and obtained good results for several distinct land surfaces (Albertson et al., 1995; De Bruin and Hartogensis, 2005; von Randow et al., 2006). 
The variance method allows the $\mathrm{H}$ estimate once provided the $\sigma_{\mathrm{T}}$ measurements, based on the MOST (Katul et al., 1995):

$$
\mathrm{H}_{\mathrm{var}}=\rho \mathrm{c}_{\mathrm{p}}\left(\frac{\sigma_{\mathrm{T}}}{0.97}\right)^{3 / 2}\left(\frac{\kappa \mathrm{gz}}{\mathrm{T}}\right)^{1 / 2} \text { for } \zeta<0
$$

Before applying the variance method, the relationship between $\sigma_{\mathrm{T}} / \mathrm{T}_{*}$ and $\zeta$ has been computed (Fig. 3). Therefore, the universal function $\phi_{\mathrm{T}}(\zeta)$ (Eq. 2b) has been obtained by least square method. The fitting curve resulting for the Pantanal data under unstable conditions is:

$$
\phi_{\mathrm{T}}(\zeta)=(0.02-0.65 \zeta)^{-1 / 3} \text { for } \zeta<0
$$

Figure (3) shows the associated fitting of $\phi_{\mathrm{T}}(\zeta)$ that is comparable to the proposed by Albertson et al. (1995) and Andreas et al. (1998). Under free convection condition $(\zeta<-2), \phi_{\mathrm{T}}(\zeta)$ tends to the asymptotic behavior $\zeta^{-1 / 3}$ as $\zeta \rightarrow-\infty$, as predicted by Wyngaard et al. (1971).

The normalized standard deviation $\sigma_{\mathrm{T}} / \mathrm{T}_{*}$, under neutral condition, shows a large scattering because $\sigma_{\mathrm{T}}$ and $\mathrm{T}_{*}$ are both varying close to zero, and consequently the experimental accuracy is expected to be very low (Pahlow et al., 2001; De Bruin and Hartogensis, 2005). Another aspect that contributes to this the larger scattering is the temperature fluctuations associated to the thermal heterogeneities, which can exist even if the $\mathrm{H}$ is almost zero in a mean sense (Kader and Yaglom, 1990; Tsvang et al., 1998).

Under stable condition, even with the scattering of the points (Fig. 3), $\sigma_{\mathrm{T}} / \mathrm{T}_{*}$ tends asymptotically to $2.64 \pm 0.56$, which agrees with the empirical values 2.9 and 3.0 proposed by De Bruin et al. (1993) and Pahlow et al. (2001), respectively.

Mahrt (1999) provides one complete list of problems found under stable condition. Particularly, the evaluation of the MOST should contain a significant contribution of the 
self-correlation (Mahrt et al., 1998; Klipp and Mahrt, 2004; Baas et al., 2006) and there is enormous difficult for achieving the universal fit or parameterization. The selfcorrelation problem will be discussed in details to the standard deviation of wind velocity components in subsection $b$.

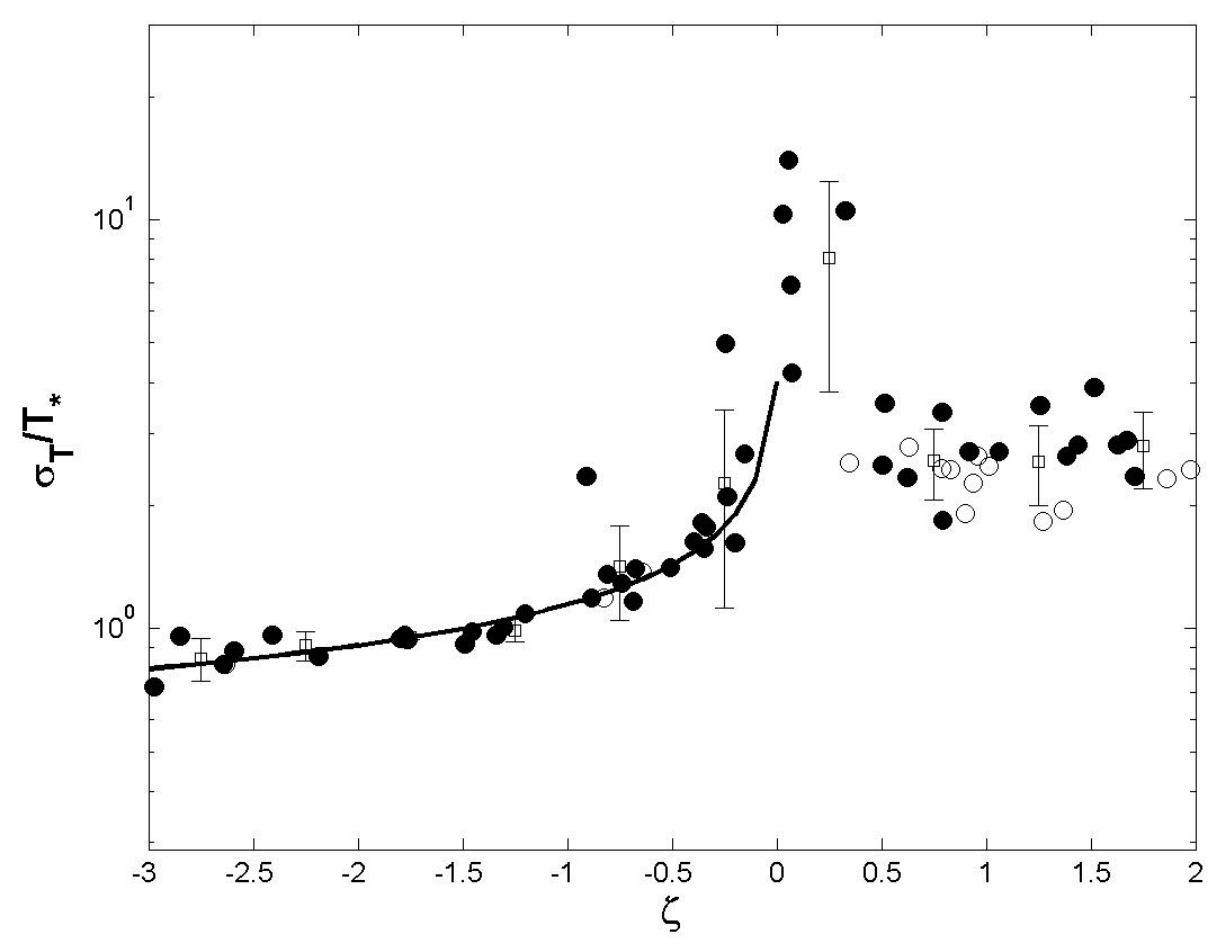

Figure 3 - Normalized standard deviation of the temperature as a function of the stability parameter and the respective standard deviation bars. The black bold line represents $\phi_{\mathrm{T}}(\zeta)$ (Eq. 6). The solid and open circles represent the stationary and nonstationary data, respectively.

Since $\phi_{\mathrm{T}}(\zeta)$ had been determined under unstable condition (Eq. 6), the sensible heat flux is estimated by two independent methods, $\mathrm{H}_{\text {eddy }}$ and $\mathrm{H}_{\text {var }}$, as presented in the Fig. (4). The slope of the linear regression fit, forced through the origin, is 1.02 and coefficient of determination of 0.96 . This result is in agreement with the ones found by 
Albertson et al. (1995) and Katul et al. (1995), obtained over uniform and non-uniform terrain

Hence, the MOST is able to describe the heat transport relationships on the Pantanal region, at least approximately. Indeed, the variance method, that is based on simple measurements of first and second moments of $\mathrm{T}^{\prime}$, allows accurate estimates of $\mathrm{H}$ under unstable conditions, even over heterogeneous surfaces such as Pantanal, without direct w' measurements.

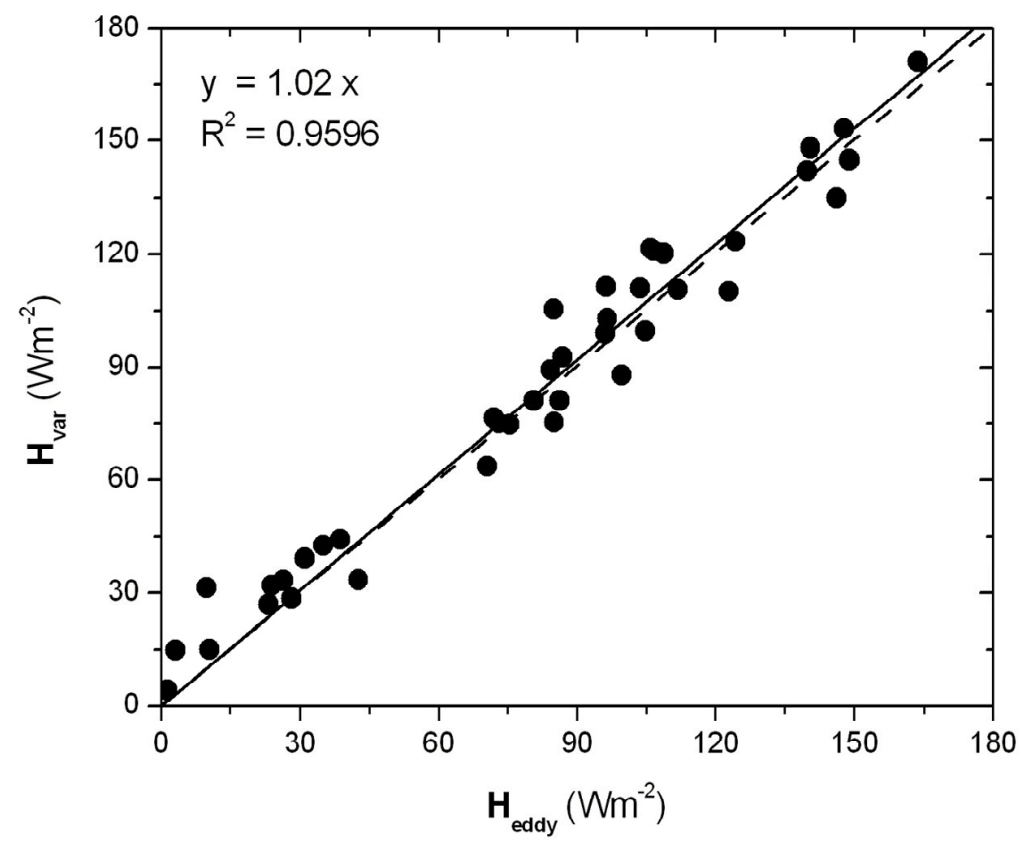

Figure 4 - Comparison between sensible heat flux values estimated by EC $\left(\mathrm{H}_{\text {eddy }}=\rho \mathrm{c}_{\mathrm{p}} \overline{\mathrm{w}^{\prime} \mathrm{T}^{\prime}}\right)$ and variance $\left(\mathrm{H}_{\mathrm{var}}\right)$ methods (Eq. 5). The lines represent: linear regression fit (solid) and identity function (dashed).

\section{b) Standard deviation of wind velocity}

The standard deviation of the wind velocity components provides some useful information about the turbulence intensity. They are also very important to validate the 
modeling of kinetic energy and turbulent transport in the planetary boundary layer (PBL) (Wyngaard, 1983).

For neutral conditions, the MOST predicts the invariance of the normalized standard deviation of the wind velocity components, $\sigma_{\mathrm{u}, \mathrm{v}, \mathrm{w}} / \mathrm{u}_{*}$ (Panofsky and Dutton, 1984). The Table 1 presents the estimations of $\sigma_{\mathrm{u}, \mathrm{v}, \mathrm{w}} / \mathrm{u}_{*}$ under neutral stability condition on Pantanal compared to other estimations reported in the literature. There is a first order agreement between the available estimates. The observed differences occur probably due to the terrain characteristics, such as land use, non-turbulent motion contributions, instrumental errors, and different heights of measurements (Panofsky and Dutton, 1984; Kader and Yaglom, 1990; Högström, 1990; Al-Jiboori et al., 2001; Högström et al., 2002).

Table 1 - Normalized standard deviations of the wind velocity components under neutral stability condition

\begin{tabular}{cccl}
\hline$\sigma_{\mathrm{w}} / \mathrm{u}_{*}$ & $\sigma_{\mathrm{u}} / \mathrm{u}_{*}$ & $\sigma_{\mathrm{v}} / \mathrm{u}_{*}$ & \multicolumn{1}{c}{ References } \\
\hline $1.33 \pm 0.02$ & $2.21 \pm 0.03$ & $1.76 \pm 0.03$ & Pantanal Region \\
1.20 & 2.40 & 2.20 & Moraes et al. (2005) \\
1.37 & $2.32 \pm 0.39$ & $2.29 \pm 0.22$ & Krishnan and Kunhikrishnan (2002) \\
1.10 & 2.30 & 2.00 & Pahlow et al. (2001) \\
1.20 & 2.55 & - & Andreas et al. (1998) \\
- & $2.78 \pm 0.25$ & $2.44 \pm 0.40$ & Högström (1990) \\
1.25 & 2.70 & 2.50 & Kader and Yaglom (1990) \\
$1.25 \pm 0.03$ & $2.39 \pm 0.03$ & $1.92 \pm 0.05$ & Panofsky and Dutton (1984) \\
1.30 & - & - & Merry and Panofsky (1976) \\
1.25 & 2.30 & 1.70 & Monin and Yaglom (1971) \\
\hline
\end{tabular}

The MOST predicts that the normalized standard deviation of the wind velocity components are functions of $\zeta$ (Kader and Yaglom, 1990; Andreas et al., 1998). 
The Fig. 5 shows $\sigma_{\mathrm{w}} / \mathrm{u}_{*}$ as a function of $\zeta$ for the Pantanal, and the resulting fitting curves:

$$
\begin{array}{ll}
\phi_{\mathrm{w}}(\zeta)=(1.58-3.86 \zeta)^{1 / 3} & \text { for } \zeta<0 \\
\phi_{\mathrm{w}}(\zeta)=(1.16+0.12 \zeta) & \text { for } \zeta>0
\end{array}
$$

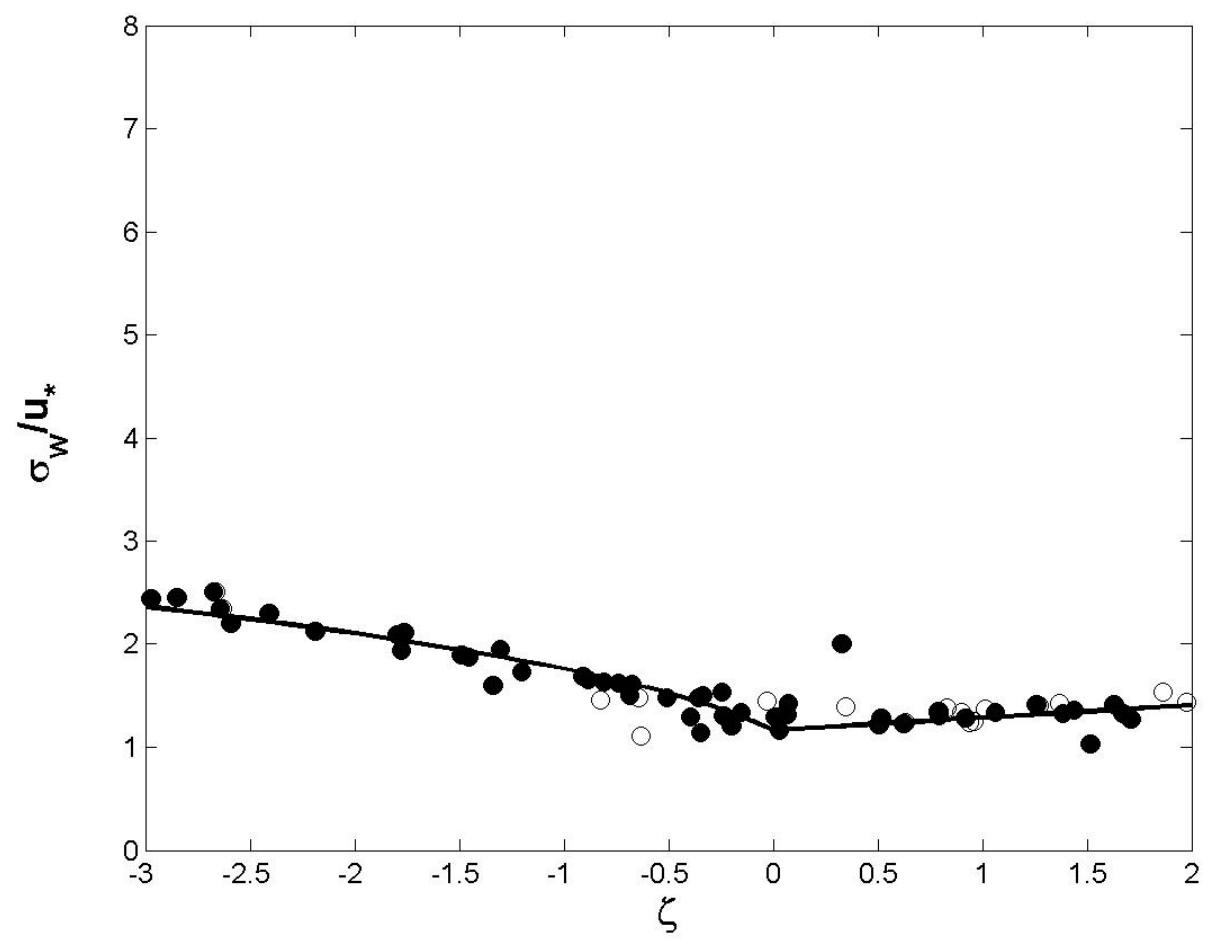

Figure 5 - Normalized standard deviation of the vertical wind velocity as a function of the stability parameter. The solid line represents $\phi_{\mathrm{w}}(\zeta)$ (Eqs. 7a and 7b). The solid and open circles represent the stationary and non-stationary data, respectively.

The $\phi_{\mathrm{w}}(\zeta)$ obtained are lightly inferior to the curve proposed by Panofsky et al. (1977) and Kaimal and Finnigan (1994), under unstable and stable conditions, respectively. Towards free convection, $\sigma_{w} / u_{*}$ increase obeying the $1 / 3$ power-law as predict from the literature (Wyngaard et al., 1971). 
The normalized standard deviation of the horizontal wind velocity $\sigma_{U} / u_{*}$ (where $\sigma_{\mathrm{U}}^{2}=0.5\left[\sigma_{\mathrm{u}}^{2}+\sigma_{\mathrm{v}}^{2}\right]$ ) as a function of $\zeta$ is showed in the Fig. 6 . The fitting curves obtained for the Pantanal are given by:

$$
\begin{array}{ll}
\phi_{U}(\zeta)=(5.23-7.94 \zeta)^{1 / 3} & \text { for } \zeta<0 \\
\phi_{U}(\zeta)=(1.74+0.36 \zeta) & \text { for } \zeta>0
\end{array}
$$

For stable conditions, $\phi_{\mathrm{U}}(\zeta)$ presents good agreement with the curve proposed by Andreas et al. (1998), despite the complexity of the atmospheric turbulent regime, global intermittence, non-turbulent motion contributions and low level jet effects (Mahrt et al., 1998; Mahrt, 1999; Poulos et al., 2002; Sun et al., 2004). Under unstable conditions, $\zeta>-2$, the estimates of $\sigma_{U} / u_{*}$ seems to follow the MOS predictions very well (Kader and Yaglom, 1990).

On the other hand, under free convection, some empirical evidences show that the horizontal velocity fluctuations are influenced by large convectively driven eddies, extending up to the top of the PBL. They suggest that both scales, the PBL height $z_{i}$ and the convective velocity scaling $\mathrm{w}_{*}=\left[\left(\mathrm{g} / \mathrm{T}_{0}\right)\left(\overline{\mathrm{w}^{\prime} \mathrm{T}^{\prime}}\right)_{0} \mathrm{z}_{\mathrm{i}}\right]^{1 / 3}$, are more appropriated scaling parameters than $\mathrm{z}$ and $\mathrm{u}_{*}$ for normalizing the horizontal wind velocity fluctuations in the unstable SL (Deardorff, 1972; Panofsky et al., 1977; Kaimal, 1978; Johansson et al., 2001).

During the IPE-1 campaign, the PBL vertical structure data were not available, and direct measurements of the PBL height have not been performed. Then, a mixed layer (ML) slab model (Tennekes, 1973; Oliveira et al., 2004) has been used to estimate $z_{\mathrm{i}}$ under strong convective conditions. A top-down entrainment rate of $20 \%$ of the Pantanal surface heat flux $\mathrm{H}_{\text {eddy }}$ is applied. The temporal evolution of $\mathrm{H}_{\text {eddy }}$ has been 
assimilated by a Newtonian's nudging (Haltiner and Williams, 1980) as a boundary condition forcing of the ML slab model. The Tennekes' model is based in the integration of the temperature equation along the vertical levels of ML, considering the application of integral differencing rule.

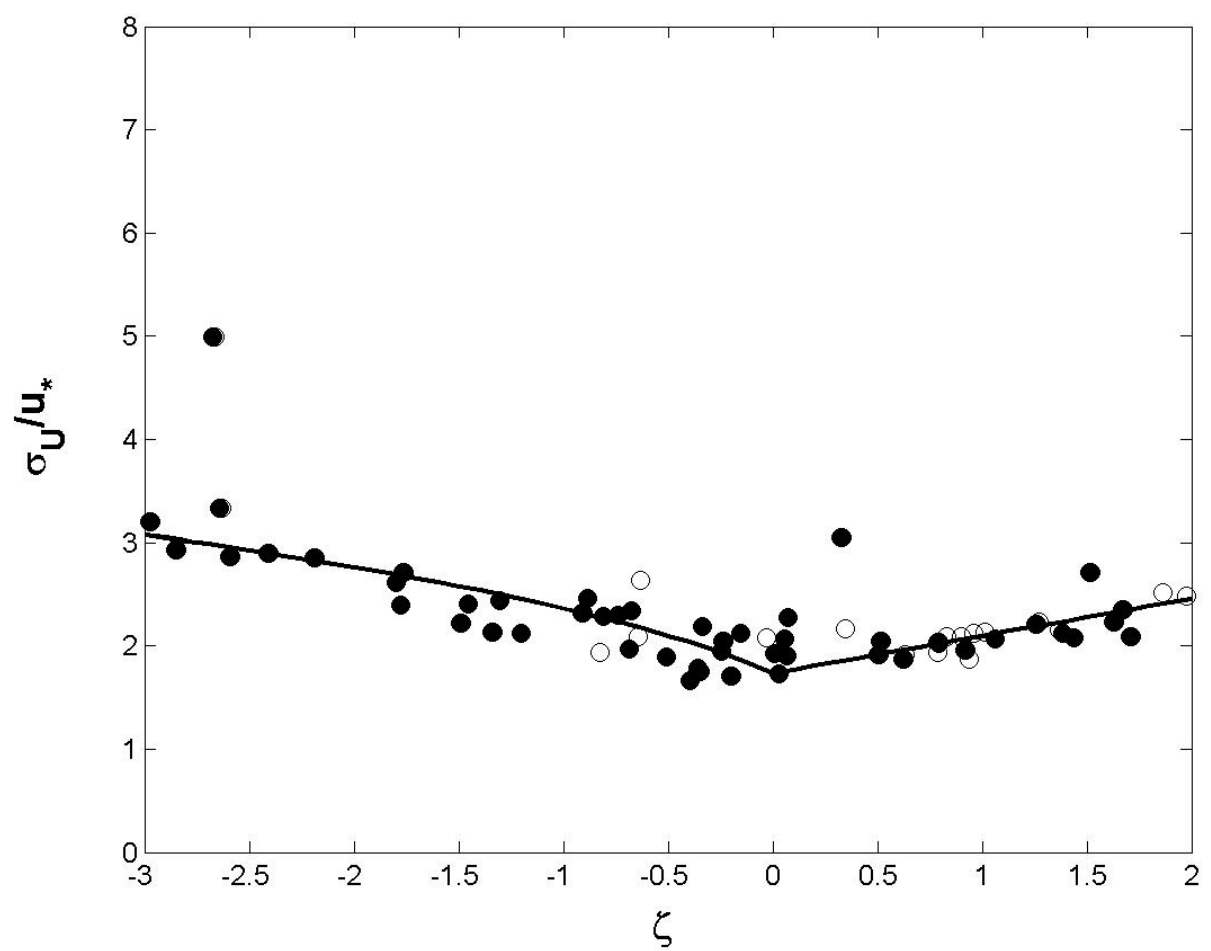

Figure 6 - Normalized standard deviation of the horizontal wind velocity as a function of the stability parameter. The solid lines represent $\phi_{U}(\zeta)$ (Eqs. 8a and 8b). The solid and open circles represent the stationary and non-stationary data, respectively.

In the Fig. $7 \sigma_{U} / \mathrm{w}_{*}$ has been plotted against $\mathrm{z}_{\mathrm{i}} / \mathrm{L}$ under free convection, where the solid line represents the fitting curve given by:

$$
\frac{\sigma_{\mathrm{U}}}{\mathrm{W}_{*}}\left(\frac{\mathrm{z}_{\mathrm{i}}}{\mathrm{L}}\right)=\left(0.31-\frac{3.00}{\mathrm{z}_{\mathrm{i}} / \mathrm{L}}\right)^{1 / 3} \text { for } \mathrm{z}_{\mathrm{i}} / \mathrm{L}<0 \text { and } \zeta<-2
$$

which is in agreement with the proposed formulation by Johansson et al. (2001). 
In order to verify what it is the better adjustment between Eq. (8a) and (9), a RMSE analysis was performed. The RMSE of $\sigma_{U} / u_{*} \times \zeta$ and $\sigma_{U} / w_{*} \times z_{i} / L$ were calculated (Table 2) considering fitting curves defined by least square methods. The results confirm the statement $z_{i}$ and not $\mathrm{z}$ is the main characteristic length scale under free convection.

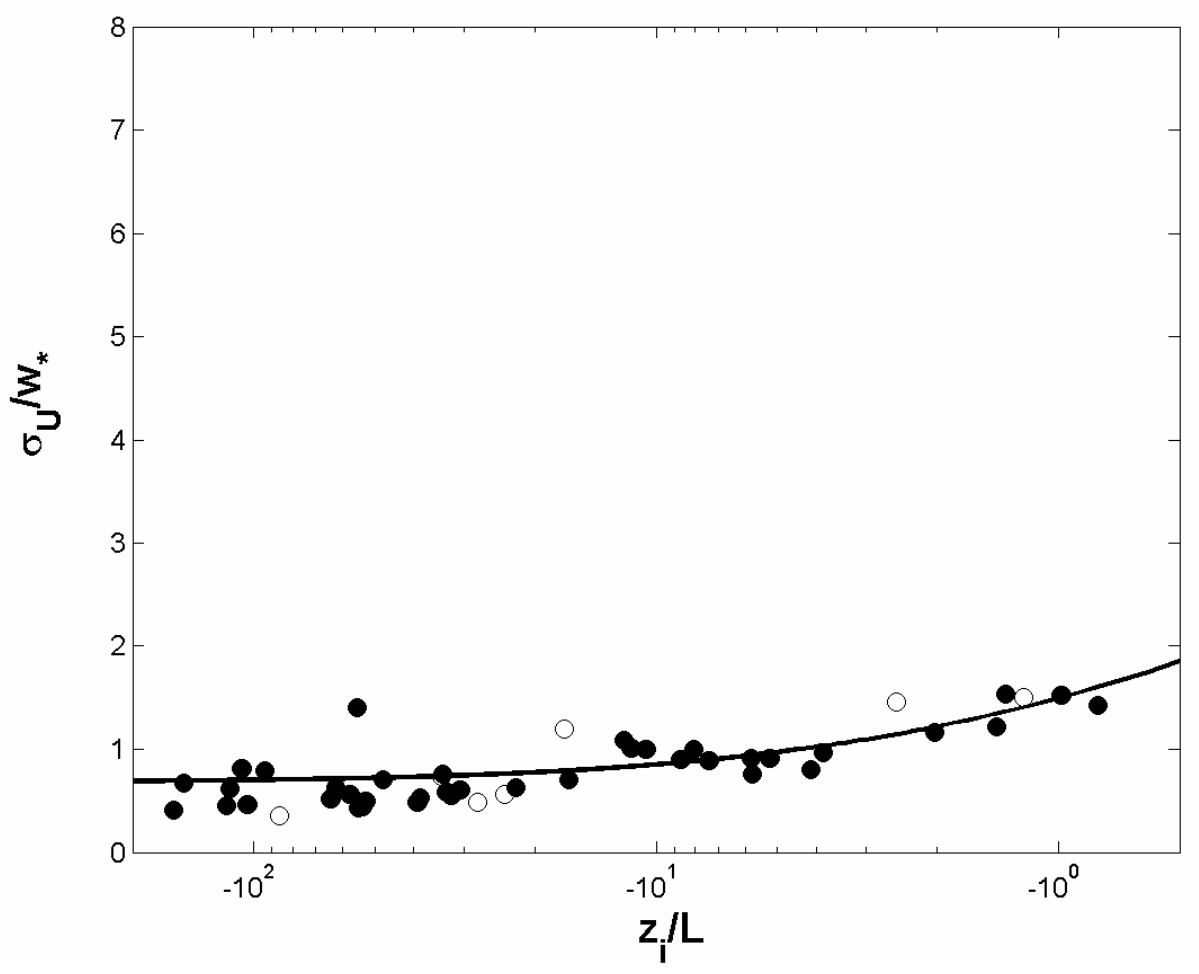

Fig. 7 - Normalized standard deviation of the horizontal wind velocity as a function of the stability parameter $z_{i} / L$. The solid line represents $\sigma_{U} / w_{*}$ (Eq. 9). The solid and open circles represent the stationary and non-stationary data, respectively.

Table 2 - RMSE estimated for normalized standard deviation of the wind velocity components under free convection condition

\begin{tabular}{ccc}
\hline$-30 \leq \zeta \leq-2$ & $\sigma_{\mathrm{U}} / \mathrm{u}_{*}$ & $\sigma_{\mathrm{U}} / \mathrm{w}_{*}$ \\
\hline $\mathrm{RMSE}$ & 1.01 & 0.25 \\
\hline
\end{tabular}


Kader and Yaglom (1990) had discussed the validity of MOST in function of the measurements heights at relatively smaller. They affirm $z_{i}$ is the correct length scale when the measurements are made at heights greater than the thickness of the SL.

Despite of the relative success of the universal functions defined by MOST in representing the standard deviation of the wind velocity components under stable condition, Mahrt et al. (1998) have reasoned that the relationships can be strongly influenced by self-correlation due to the occurrence of $\mathrm{u}_{*}$ on both sides of the Eqs. (7b and $8 b)$.

According to Klipp and Mahrt (2004) (see their Fig. 2, page 2092), our original set of variables $\mathrm{u}_{*}, \overline{\mathrm{w}^{\prime} \mathrm{T}^{\prime}}, \overline{\mathrm{w}^{\prime} \mathrm{q}^{\prime}}, \sigma_{\mathrm{U}, \mathrm{w}}$ was redistributed in a random and independent way for every variable. This generated a new set of variables with dimension 10 times larger than the original set that presents the same average and variance.

The linear-correlation coefficient estimated for the original set $\left(\mathrm{R}_{\text {data }}\right)$ and the randomized set $\left(\mathrm{R}_{\text {rand }}\right)$ point out that the variance explained by self-correlation is smaller. In the other hand, the same analysis procedure (Table 3) under stable condition, $0.1<\zeta \leq 2$, supports the idea that self-correlation is significant and the results shown in the Figs. (5 and 6) should be interpreted cautiously. Under neutral conditions, both correlations are small (not showed) and the standard deviation does not depend on $\zeta$, in according to MOST.

The correlation coefficient between two variables is determined by the ratio of their covariance and the product of their respective standard deviations. In the SL the correlation coefficients for the heat $\left(\mathrm{r}_{\mathrm{wT}}=\overline{\mathrm{w}^{\prime} \mathrm{T}^{\prime}} / \sigma_{\mathrm{w}} \sigma_{\mathrm{T}}\right)$ and momentum flux $\left(\mathrm{r}_{\mathrm{uw}}=\overline{\mathrm{u}^{\prime} \mathrm{w}^{\prime}} / \sigma_{\mathrm{u}} \sigma_{\mathrm{w}}\right)$ are following the MOST (Kaimal et al., 1972; Kaimal and Finnigan, 
1994). The estimations for the Pantanal are showed in the Figs. 8a and 8b, respectively, where the solid line represents the following fitting curve:

$$
\begin{array}{ll}
\mathrm{r}_{\mathrm{wT}}(\zeta)=0.81\left[\frac{1}{1+\mathrm{e}^{5(\zeta+0.10)}}\right]-0.30 & \text { for }-3 \leq \zeta \leq 2 \\
\mathrm{r}_{\text {uw }}(\zeta)=0.18\left[\frac{1}{1+\mathrm{e}^{5(\zeta+1.25)}}\right]-0.32 & \text { for }-3 \leq \zeta \leq 2
\end{array}
$$

Table 3 - Self-correlation analysis

\begin{tabular}{c|cc|cc}
\hline \multirow{2}{*}{$\begin{array}{c}\text { Stability } \\
\text { conditions }\end{array}$} & \multicolumn{2}{|c|}{$\sigma_{\mathrm{w}} / \mathrm{u}_{*}$} & \multicolumn{2}{c}{$\sigma_{\mathrm{U}} / \mathrm{u}_{*}$} \\
\cline { 2 - 5 } & $\mathrm{R}_{\text {data }}$ & $\mathrm{R}_{\mathrm{rand}}$ & $\mathrm{R}_{\text {data }}$ & $\mathrm{R}_{\text {rand }}$ \\
\hline$-3 \leq \zeta<-0.1$ & -0.93 & -0.13 & -0.78 & -0.15 \\
$0.1<\zeta \leq 2$ & -0.08 & 0.44 & 0.29 & 0.50 \\
\hline
\end{tabular}

Under unstable conditions the correlation coefficients are $r_{\mathrm{wT}}=0.45 \pm 0.03($ for $-2<\zeta<0)$ and $\mathrm{r}_{\mathrm{uw}}=-0.31 \pm 0.02($ for $-1<\zeta<1)$ in agreement with the values proposed by Kaimal and Finnigan (1984) for Kansas experiment, $\mathrm{r}_{\mathrm{wT}} \simeq 0.5($ for $-2<\zeta<0)$ and $\mathrm{r}_{\mathrm{uw}} \simeq-0.35$ (for $\left.-1<\zeta<1\right)$, respectively.

In according to Högström (1990), $\left|\mathrm{r}_{\mathrm{uw}}\right|<0.30$ indicates the presence of inactive turbulence associate to the transport of turbulent energy from the layer above by the pressure transport term. Similar results have been found by von Randow et al. (2006) in the SL over the Amazonian rain forest. In the Pantanal the correlation coefficients found is near to the expected, and the low frequency contributions seems to be smaller, at least in the range $-3<\zeta<2$ and for $60 \mathrm{~min}$ averaging time scale. 

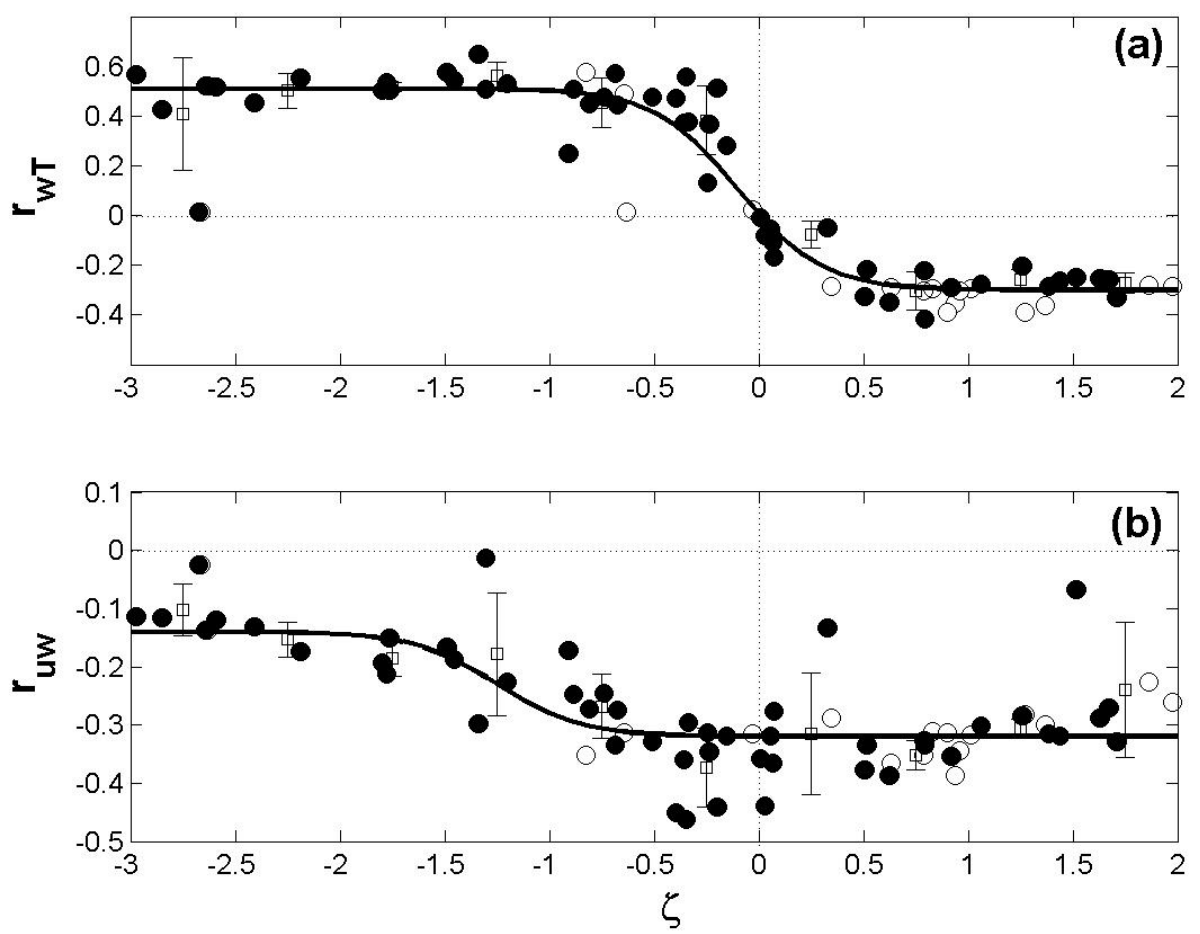

Fig. 8 - Correlation coefficients with the standard deviation bars for: a) heat flux $r_{w T}$; ) momentum flux $r_{u w}$. The solid lines represent the fitting curves for Pantanal (Eqs. 10a and $10 \mathrm{~b}$ ). The solid and open circles represent the stationary and non-stationary data, respectively.

\section{Conclusions}

The SEB components, the standard deviations of the wind velocity, the standard deviations of the temperature, and the correlation coefficients have been computed above the complex terrain found in Pantanal region in Brazil.

The analysis considers the micrometeorological measurements recorded during the IPE-1 over a vegetated terrain partially covered by a SWL with 7 to $15 \mathrm{~cm}$-depth. The SWL contains a lot of embedded vegetation. The presence of vegetation implies a specific radiation transfer through the depth of the water body and a particular energy budget. 
The surface fluxes $H, R_{n}$ and $G_{\text {out }}$ were measured directly, LE and $\Delta S$ were estimated by the Bowen ratio method and as a residual term, respectively. The diurnal evolution of SEB components should be understood as a consequence of the great surface heating of SWL and the large LE $(\beta \approx 0.36 \pm 0.01)$.

The determination of $\mathrm{d}$ follows the methodology proposed by De Bruin and Verhoef (1997) based in the $\sigma_{\mathrm{w}}$ under free convection, resulting the value $4.96 \pm 0.56$.

The MOST predicts the behavior of the normalized standard deviations, under unstable condition, above the Pantanal surface. Both $\sigma_{\mathrm{U}, \mathrm{w}} / \mathrm{u}_{*}$ and $\sigma_{\mathrm{T}} / \mathrm{T}_{*}$ are comparable to those found in the literature. The comparison between $\mathrm{H}$ values estimated by EC and variance method indicates the general applicability of the MOST for describing the sensible heat flux.

Under neutral condition all normalized standard deviations shows a greater scattering, likely associated with the surface heterogeneities, non-turbulent motions, and instrumental errors. For stable condition, the estimates can be strongly influenced by self-correlation. In the limit of the free convection regime, the proper characteristic scales to normalize $\sigma_{\mathrm{U}}$ are $\mathrm{z}_{\mathrm{i}}$ and $\mathrm{W}_{*}$. The correlation coefficients are in agreement with the values proposed in the literature. Particularly, the presence of low frequency contributions was not identified.

\section{Acknowledgements}

Our thanks are due to the anonymous reviewers and the following people that participated in the IPE-1, Dr. Antonio Ocimar Manzi (coordinator), Dr. Kolavennu Panduranga Vittal Murthy, Dr. Yadvinder Malhi, Dr. Bart Kruijt and other scientists, students and collaborators. Special thanks also go to Daniele Santos Nogueira from Universidade Federal do Pará for valuable comments. This work is part of the 
Interdisciplinary Pantanal Experiment and was supported by the Fundação do Amparo à

Pesquisa do Estado de São Paulo (FAPESP), Brazil. The authors are also grateful to the

Conselho Nacional de Pesquisas e Desenvolvimento Tecnológico (CNPq), Universidade

Federal do Mato Grosso do Sul (UFMS), and to the Instituto Nacional de Ciências

Espaciais (INPE) - Centro de Previsão de Tempo e Estudos Climáticos (CPTEC).

\section{References}

Albertson, J.D., Parlange, M.B., Katul, G.G., Chu, C.-R., Stricker, H., Tyler, S., 1995. Sensible heat flux from arid regions: A simple flux-variance method. Water Resources Research, 31, 969-973.

Al-Jiboori, M.H., Xu, Y., Qian, Y., 2001. Effects of different terrain on velocity standard deviations. Atmospheric Science Letters, 2, 25-31.

Andreas, E.L., Hill, R.J., Gosz, J.R., Moore, D.I., Otto, W.D., Sarma, A.D., 1998. Stability dependence of the eddy-accumulation coefficients for momentum and scalars. Boundary-Layer Meteorology, 86, 409-420.

Baas, P., Steeneveld, G. J., Van de Wiel, B. J. H., Holtslag, A. A. M., 2006. Exploring self-correlation in flux-gradient relationships for stably stratified conditions. Journal of the Atmospheric Sciences, 63, 3045-3054.

Daubechies, I., 1992. Ten lectures on wavelets. Philadelphia: SIAM, 357 p.

De Bruin, H. A. R., Kohsiek, W., van den Hurk, J. J. M., 1993. A verification of some methods to determine the fluxes of momentum, sensible heat, and water vapour using standard deviation and structure parameter of scalar meteorological quantities. Boundary-Layer Meteorology, 63, 231-257.

De Bruin, H.A.R., Verhoef, A., 1997. A new method to determine the zero-plane displacement. Boundary-Layer Meteorology, 82, 159-164.

De Bruin, H.A.R., Hartogensis, O.K., 2005.Variance method to determine turbulent fluxes of momentum and sensible heat in the stable atmospheric surface layer. Boundary-Layer Meteorology, 116, 385-392.

Deardorff, J.W., 1972. Numerical investigation of neutral and unstable planetary boundary layers. Journal of the Atmospheric Sciences, 29, 91-115.

Garratt, J.R., 1980. Surface influence upon vertical profiles in the atmospheric nearsurface layer. Quarterly Journal of the Royal Meteorological Society, 450, 803-819.

Garratt, J. R., 1992. The atmospheric boundary layer. Cambridge: Cambridge University, $316 \mathrm{p}$.

Haltiner, G.J., Williams, R.T., 1980. Numerical prediction and dynamic meteorology. New York: John Wiley \&. Sons, 397 p. 
Hamilton, S.K., Sippel, S.J., Melack, J.M., 1996. Inundation patterns in the Pantanal wetland of South America determined from passive microwave remote sensing. Arch. Hydrobiol., 137, 1-23.

Högström, U., 1990. Analysis of turbulence structure in the surface layer with a modified similarity formulation for near neutral conditions. Journal of the Atmospheric Sciences, 47, 1949-972.

Högström, U. 1996. Review of some basic characteristics of the atmospheric surface layer. Boundary-Layer Meteorology, 78, 215-246.

Högström, U., Hunt, J.C.R., Smedman,A.-S., 2002. Theory and measurements for turbulence spectra and variances in the atmospheric neutral surface layer. Boundary-Layer Meteorology, 103, 101-124.

Jacobs, A.F.G., Jetten, T.H., Lucassen, D.C., Heusinkveld, B.G., Nieveen, J.P., 1997. Diurnal temperature fluctuations in a natural shallow water body. Agricultural and Forest Meteorology, 88, 269-277.

Johansson, C., Smedman, A.-S., Högström, U., 2001. Critical test of the validity of Monin-Obukhov similarity during convective conditions. Journal of the Atmospheric Sciences, 58, 1549-1566.

Junk, W.J., Cunha, C.N., 2005. Pantanal: a large South American wetland at a crossroads, Ecological Engineering, 24, 391-401.

Kader, B.A., Yaglom, A.M., 1990. Mean fields and fluctuation moments in unstably stratified turbulent boundary layers. Journal of Fluid Mechanics, 212, 637-662.

Kaimal, J. C., Wyngaard, J. C., Izumi, Y, Coté, O. R., 1972. Spectral characteristics of surface-layer turbulence. Quarterly Journal of the Royal Meteorological Society, 98, 563-589.

Kaimal, J.C., 1978. Horizontal velocity spectra in an unstable surface layer. Journal of the Atmospheric Sciences, 35, 18-24.

Kaimal, J.C., Wyngaard, J.C., 1990. The Kansas and Minnesota experiments. Boundary-Layer Meteorology, 50, 31-47.

Kaimal, J.C., Finnigan, J.J., 1994. Atmospheric boundary layer flows: Their structure and measurement. New York: Oxford-University, 289 p.

Katul, G.G., Goltz, S.M., Hsieh, C.I., Cheng, Y., Mowry, F., Sigmon, J., 1995. Estimation of surface heat and momentum fluxes using the flux-variance method above uniform and non-uniform terrain. Boundary-Layer Meteorology, 74, 237260.

Khanna, S., Brasseur, J.G., 1997. Analysis of Monin-Obukhov similarity from largeeddy simulation. Journal of Fluid Mechanics, 345,251-286.

Klipp, C. L., Marht, L., 2004. Flux-gradient relationship, self-correlation and intermittency in the stable boundary layer. Quarterly Journal of the Royal Meteorological Society, 130, 2087-2103.

Krishnan, P., Kunhikrishnan, P.K., 2002. Some characteristics of atmospheric surface layer over a tropical inland region during southwest monsoon period. Atmospheric Research, 62, 111-124. 
Liu, H., Foken, T., 2001. A modified Bowen ratio method to determine sensible and latent heat fluxes. Meteorologische Zeitschrift, 10, 71-80.

Lloyd, C.R., Culf, A.D., Dolman, A.J., Gash, J.H.C., 1991. Estimates of sensible heat flux from observations of temperature fluctuations. Boundary-Layer Meteorology, $57,311-322$.

Mahrt, L., Macpherson, J. I., Desjardins, R., 1994. Observations of fluxes over heterogeneous surfaces. Boundary-Layer Meteorology, 67, 345-367.

Mahrt, L., Sun, J., Blumen, W., Delany, T., Oncley, S., 1998. Nocturnal boundary-layer regimes. Boundary-Layer Meteorology, 88, 255-278.

Mahrt, L.,1998. Flux sampling errors for aircraft and towers. Journal of Atmospheric and Oceanic Technology, 15, 416-429.

Mahrt, L., 1999. Stratified atmospheric boundary layer. Boundary-Layer Meteorology, 90, 375-396.

Merry, M., Panofsky, H.A., 1976. Statistics of vertical motion over land and water. Quarterly Journal of the Royal Meteorological Society, 102, 255-260.

Monin, A.S., Yaglom, A.M., 1971. Statistical fluid mechanics: mechanics of turbulence. Massachussets: MIT, 769 p.

Moraes, O.L.L., Acevedo, O.C., Degrazia, G.A., Anfossi, A., Silva, R., Anabor, V. , 2005. Surface layer turbulence parameters over a complex terrain. Atmospheric Environment, 39, 3103-3112.

Oke, T.R., 1987. Boundary Layer Climates. Methuen: London, 435 p.

Oliveira, A. P., Soares, J., Karam, H. A., Pereira, M. M. R., Marques Filho, E. P., 2004. Numerical modeling of the planetary boundary layer. Revista Brasileira de $\begin{array}{llll}\text { Engenharia Térmica, } & \text { 5, }\end{array}$ (http://www.iag.usp.br/meteo/labmicro/Oliveira_et_al_2004_NUMERICAL MODELING OF THE PLANETARY BOUNDARY LAYER.pdf).

Otnes, R. K., Enochson, L., 1972. Digital time series analysis. New York: John Wiley \& Sons, $467 \mathrm{p}$.

Pahlow, M., Parlange, M.B., Porté-Agel, F., 2001. On Monin-Obukhov similarity in the stable atmospheric boundary layer. Boundary-Layer Meteorology, 99, 225-248.

Panofsky, H.A., Tennekes, H., Lenschow, D.H., Wyngaard, J.C., 1977. The characteristics of turbulent velocity components in the surface layer under convective conditions. Boundary-Layer Meteorology, 11, 355-361.

Panofsky, H.A., Dutton, J.A., 1984. Atmospheric turbulence. New York: John Wiley \&. Sons, $397 \mathrm{p}$.

Por, F.D., 1995. The Pantanal of Mato Grosso (Brazil). Dordrecht: K. A. Publishers, $122 \mathrm{p}$.

Poulos, G.S., Blumen, W., Fritts, D.C., Lundquist, J. K., Sun, J., Burns, S.P., Nappo, C., Banta, R., Newsom, R., Cuxart, J., Terradellas, E., Balsley, B., Jensen, M., 2002. CASES-99: A comprehensive investigation of the stable nocturnal boundary layer. Bulletin of the American Meteorological Society, 83, 555-581. 
Raupach, M.R., Finnigan, J.J., Brunet, Y. 1996. Coherent eddies and turbulence in vegetation canopies: the mixing-layer analogy.Boundary-Layer Meteorology, 78, 351-382.

Sorbjan, Z., 1986. On similarity in the atmospheric boundary layer. Boundary-Layer Meteorology, 35, 377-397.

Sorbjan, Z., 1989. Structure of the Atmospheric Boundary Layer, Prentice-Hall, London, $317 \mathrm{pp}$.

Sun, J., Howell, J.F., Esbensen, S.K., Mahrt, L., Greb, C.M., Grossman, R., LeMone, M.A., 1996. Scale dependence of air-sea fluxes over the western Equatorial Pacific. Journal of the Atmospheric Sciences, 53, 2997-3012.

Sun, J., Lenschow, D.H., Burns, S.P., Banta, R.M., Newsom, R.K., Coulter, R., Nappo, C., Balsley, B.B., Jensen, M., Mahrt, L., Miller, D., Skelly, B., 2004. Atmospheric disturbances that generate intermittent turbulence in nocturnal boundary layers. Boundary-Layer Meteorology, 110, 255-279.

Shuttleworth, J., Gash, J.H.C., Lloyd, C.R., Moore, C.J., Roberts, J., Marques Filho, A.O., Fisch, G., Silva Filho, V.P., Ribeiro, M.N.G., Molion, L.C.B., Sá, L.D.A., Nobre, C.A., Cabral, O.M.R., Patel, S.R., Moraes, J.C., 1984. Eddy correlation measurements of energy partition for Amazonian forest. Quarterly Journal of the Royal Meteorological Society, 110, 1143-1162.

Tennekes, H., 1973. A model for the dynamics of the inversion above a convective boundary layer. Journal of the Atmospheric Sciences, 30, 558-567.

Thom, A.S., 1975. Momentum, mass and heat exchange of plant communities. In: J. L. Monteith ed., Vegetation and the atmosphere. London : Academic, 57-110.

Thom, A.S., Stewart, J.B., Oliver, H.R., Gash, J.H.C., 1975. Comparison of aerodynamic and energy budget estimates of fluxes over a pine forest. Quarterly Journal of the Royal Meteorological Society, 427, 93-105.

Tsvang, L. R., Kukharets, V. P., Perepelkin, V.G., 1998. atmospheric turbulence characteristics over a temperature-inhomogeneous land surface. Part II: The effect of small-scale inhomogeneities of surface temperature on some characteristics of the atmospheric surface layer. Boundary-Layer Meteorology, 86, 103-124.

Vickers, D., Mahrt, L., 1997. Quality control and flux sampling problems for tower and aircraft data. Journal of Atmospheric and Oceanic Technology, 14, 512-526.

Viswanadham, Y., Molion, L.C.B., Manzi, A.O., Sá, L.D.A., Silva Filho, V.P., André, R.G.B., Nogueira, J.L.M., dos Santos, R.C., 1990. Micrometeorological measurements in Amazon Forest during GTE/ABLE-2A Mission. Journal of Geophysical Research, 95, D9, 1,669-13,682.

von Randow, C., Sá, L.D.A., Gannabathula, S.S.D.P., Manzi, A.O., Arlino, P.R.A., Kruijt, B., 2002. Scale variability of atmospheric surface layer fluxes of energy and carbon over a tropical rain forest in southwest Amazonia. I. Diurnal Conditions. Journal of Geophysical Research, 107, D20, LBA 29-1/29-12.

von Randow, C., Kruijt, B., Holtslag, A.A.M., 2006. Low-frequency modulation of the atmospheric surface layer over Amazonian rain forest and its implication for similarity relationship. Agricultural and Forest Meteorology, 141,192-207. 
Wieringa, J., 1993. Representative roughness parameters for homogeneous terrain. Boundary-Layer Meteorology, 63, 323-363.

Wyngaard, J.C., Coté, O.R., Izumi, Y., 1971. Local free convection, similarity, and budgets of shear stress and heat flux. Journal of the Atmospheric Sciences, 28, 1171-1182.

Wyngaard, J.C. 1983. Lectures on the planetary boundary layer. In: Lilly, D., Gal-Chen, T. ed. Mesoscale meteorology theory, observations and models. Hingham: Reidel, 603-650. 